\title{
Research on CDIO engineering education pattern microelectronics technology-driven Teaching Method
}

\author{
Lianzhong Zhang, Li Wang \\ The Donghai science and technology College of Zhejiang Ocean Universityboat , \\ mountain ,Zhejiang,316000 , China \\ email:zlz.10001@163.com
}

Keywords: CDIO, engineering education , project teaching methods, teaching Form, Research

\begin{abstract}
In this paper, Microelectronics technology Theory and Application Teaching CDIO engineering education philosophy to guide students as the main teacher-led, practice the main line, the link to the development of micro-project-driven teaching method in teaching, laboratory work and test.This articlealso made some small projects into the curriculum knowledge, guiding students to the implementation of the project CDIO engineering education model to guide the students' learning microcontroller psychological play, practice, learning, and learning in practice.Practice micro-project-driven teaching method On CDIO engineering education model is conducive to students' understanding and mastery of curriculum knowledge, train, analyze problems and problem-solving skills, improve practical skills, my creative potential to improve the overall quality. Introduction
\end{abstract}

In the 1990s, the Massachusetts Institute of Technology University to teach Sterile to "return to work" to establish a "High Quality Engineering. In 2001, the Massachusetts Institute of Technology and Chalmers Institute of Technology in Sweden, Linkoping University to And 3 of the Royal Institute of Technology and other universities jointly proposed a whole new concept of engineering education and implementation of the system-the CDIO (conceive, design, imple-ment, operate; conception, design, implementation, operation) [1-2]. CDIO workersFocus on training students to master a solid foundation of engineering theory and professional knowledge of the process of education, and this on the basis of the education process into specific contexts of engineering, design and innovative practice throughout the entire team of personnel training process training, training professional solid foundation a new generation of high level engineers and noble ethics [3]. The CDIO concept of the proposed of Universities and Colleges of applied engineering and technical personnel to provide a reference method, many colleges and universities will also be applied to the microcontroller and other technology applications courses teaching [4].Studentcentered CDIO Engineering Education Due to historical reasons, the education of our long-term by the former Soviet Kairov teaching on impact. Teachers are the main aspects of education, in a unified Personnel training mode, more emphasis on direct knowledge transfer students Ignore the cultivation of students' practical ability and innovation ability [5]. American "student-centered educational philosophy built on deep theoretical foundation of education and psychology, the theory and constructivist teaching theory is a typical representative of the teachers in the teaching process is to create a relaxed, free of learning situation, guide students to develop their own initiative, to develop their own comprehensive ability through active learning, especially the ability to innovate. CDIO engineering education model the transition from the "old three-center theory" of teachers, textbooks and classroom for student learning and learning outcomes "new center '[6], is an open teaching mode, teachers, curriculum knowledge, all penetrated into the project, and guide students through engineering practice imperceptibly to acquire new knowledge.

Old, single change in the educational model of CDIO engineering education personnel training concept to establish a product-oriented engineering values [7], the engineer should have the core of quality education as the main line of engineering education [8]. Student learning is an active cognitive process, rather than passive recipients of knowledge. The teacher's role is to guide the student initiative to acquire knowledge through practice, will get new knowledge with existing cognitive structures linked to construct the knowledge system, which is famous contemporary 
American psychologist and educator Bruner advocated "learning theory" cognitive structure.

\section{Project-driven pedagogy}

Project teaching (project teaching) is a practical teaching methods commonly used by some developed countries, led by previous teachers organizations teaching relatively fixed teaching content, is a student as the main body in the process of specific projects related teaching content to achieve the purpose of teaching a teaching mode [9]. Project pedagogy allows students "learning to do by doing" to improve the practical ability.

Many domestic colleges and universities in the form of team work is carried out in a variety of applications teaching pedagogy of the project, the advantage is the ability to cultivate student collaboration, but a lot of teachers do not pay attention to the students of engineering consciousness, the project is to develop a larger, more difficult Some of the less capable members to participate in the project group team overrepresented, making not consciousness poorer members unwilling to participate. The strong stronger and the weak weaker, "free ride" has become an unavoidable phenomenon. In view of this situation, we try to CDIO engineering education model based microprojects in the Teaching of Microcontroller Theory and Applications course driven teaching, allowing students to experience the practice in the learning process, active inquiry, something to do, everyone progress .

\section{CDIO engineering education mode of micro-projects driven teaching}

The project pedagogy and constructivist learning theory emphasizes student-centered, emphasizing the importance of real tasks or activities [10]. Learning to solve the problem is the most efficient learning. Project-driven teaching method is centered learning project (project based learning, PBL), is also a "problem-centered learning (problem based learning,PBL). Micro-projects driven teaching substance is a kind of inquiry learning model based on constructivist learning theory, teaching content knowledge

To the autonomy of the students in the real-life situation into a tiny project based exploratory learning, teachers by guiding students to work independently, to complete the project quickly. Teaching is the surface of the popularity of sex education should emphasize the development of students individual thinking, problem-solving skills, teamwork skills in academic competitions and other aspects of culture.

The conventional wisdom is that "Failure is the mother of success" that is part of working ability, strong-willed, a things the pursuit. Let students try too many failures in the teaching process, but will hit their enthusiasm for learning. "Success is the mother of success" [11], the purpose of the micro-project-driven teaching method is to let the students is slightly lacking in the middle and lower reaches of practical ability of students through efforts to quickly complete the task. Through individual efforts to build self-confidence, improve learning enthusiasm and initiative.

To the traditional teaching mode of imparting knowledge as the main goal. "Was changed to" knowledge as a carrier, capacity and quality culture as the main target in the past, the new mode, you must also implement a project-driven teaching process

CDIO engineering education philosophy. Open and independent practice in the design of microprojects, allow students to be able to carry out the project conception, design, real

Facilities and running, from passive acceptance of education to independent innovation change. Experience in the project implementation process, modern industrial product research and development from conception to operation, improved, and even the end abandoned the whole process of life.

\section{Micro-projects in the practice of pedagogy in MCU}

Microcontroller Theory and Applications ", Electrical Engineering and Automation class professional a very important application of specialized courses, practice teaching has a pivotal role in the curriculum. Micro-projects based on the CDIO work process driven teaching students the basic engineering capabilities, knowledge point of penetration into the syllabus prescribed number of micro-projects, and teachers in the entire process of tracking the implementation of the implementation of students. Student in the entire teaching process for the center, the students are active builders of knowledge significance, teachers from the organizers, instructors, help and 
promote the role [12]. Traditional teaching methods of the "bottom-up" before the foundation of professional, first microscopic after macro after the first local overall, beginners often do not know why you want to learn the course, learn what is the use of the knowledge module. In the CDIO engineering practice process, teachers should guide students to take a "top-down" engineeringoriented, day-to-day engineering design as a background, first given in the macro, the overall project concept, from macro to micro, from whole to parts, basics involved engineering expertise involved to expertise [13], to do with what, what to learn.

\section{1 .Project Preparation}

My school is located in a mountainous area of eastern Guangdong weak industrial base, a local ordinary colleges and universities, and students to purchase electronic components inconvenient. For the implementation of the project pedagogy to improve learning efficiency and effectiveness, reducing the learning intoThis design set in the hardware can be cut up to be able to finishInto 21 projects multifunctional micro-controller board. The teachers at the beginning of the semester,Find a unified circuit board production PCB board, and then shop the procurement of components. the experimental board hardware cost is about $\$ 70$, much lower than the market price, and the more expensive microcontroller, LCD, temperature sensor, dot matrix devices are pluggable, multiple students shared or other electronic systems in the repeated use [14].

2 .implementation of the project

Microcontroller Theory and Applications "course a semester for a total of 68 hours. Weak basis taking into account the part of students, in the previous three weeks (12 hours) the unified arrangement of the theoretical teaching, first a brief introduction by the teachers MCU hardware structure, the C51 language program design and assembly language Introduction program designed to allow students SCM system design preliminaryUnderstanding. Starting with the first four weeks, every two weeks ( 8 hours) to complete a project, the entire semester, a total of seven projects completed as shown in Table 1. Each project is divided into four phases, each two hours. Seven project phases and level, from easy to difficult step-by-step, and has a very good practical value. As long as the majority of students willing to spend the time, and basically be able to complete. Hardware system because all students are the same, in order to prevent student plagiarism, the design of the project, according to the students the different frame sizes, require students to use different models of single-chip crystal oscillator frequency and time parameters.

Table - curriculum implementation of micro-projects No. Item Name

1 ) LED light water design

2 ) output interface design (digital tube, dot matrix or LCD)

3 )input interface design (independent key matrix keyboard or computer keyboard)

4 )clock (timer or DS1302)

5 )SCM and computer serial communication

6 ) AD or DA design

7 ) digital temperature acquisition transmission system design (integrated project)

(1) idea (conceive) stage. Each implementation of the project, the teachers Introduce the project, explain some of the project involves the key knowledge point. Set up The project of complete openness and independent practice [15], students combine their own interests and the ability to select a specific task, and after school to prepare the relevant electronic devices, and design a good software program flow chart. "Fixed center of a circle, the radius custom core purpose of teaching methods to each student a point of attachment of divergent thinking, also to challenge the students to a certain extent on the [16] applies to the quality of students is relatively high, students The obvious gap between the general university.

(2) design (design) stage. Students find information in dormitories or laboratory welding taskrelated hardware circuit, with $\mathrm{C} 51$ or assembly language design code, Keil uVision widespread adoption of enterprise software to compile source code. During the teachers play the role of "counselor" focused guidance to individual needy students.

(3) the implementation stage (implement). Students to debug and test hardware and software interact with each other, learn from each other and improve the design of the system. Based on the 
experimental results, the preparation of the project design report. The teachers completed student projects conducted for the evaluation.

(4) run (operate) stage. Demonstrate their works in class by the students of the outstanding projects and share their experiences. Universality teachers summarize the project design process, taught lessons, and the students do a good job recognition awards.

The end of the project, the teacher and then arranged once Homework: "the uVision these two kinds simulation compiler software design corresponding project using Proteus and Keil hardware circuits and software programs.

3 .Project evaluation summary.

For each student to complete the project, teachers from the following five aspects of their assessment:

(1) hardware circuit welding process;

(2) the specification of the software program, readability and portability;

(3) overall demonstration of the effect of the combination of hardware and software;

(4) the project content and format of the summary report;

(5) language representation of the overall performance of the respondent.

Teachers strictly as long as the project evaluation link, hardware design, manufacturing, and software programs students in the process of completion of the project can not only learn to write, and to learn how to write a project report, in his reply link at the same time exercise their verbal ability. The process of completing a project, the students' comprehensive ability to improve the process.

4. project based curriculum assessment

The student curriculum Final Performance scores and final examination by the usual 2 parts. Which usually results accounted for $50 \%$, including attendance, project achievements and homework assignments; accounted for $50 \%$ of the final examination, contains the Proteus + Keil computer simulation operation examination (25\%) and in-kind production (accounting 25\%) 2 parts. Computer simulation exams taken the a fixed propositional form, requires students to design the 120min topic SCM application requirements project hardware circuits and software programs. The physical production is to take the form of an open proposition by the students own topics, using its own set of spare time Meter, making microcomputer application system PCB board welding circuit design program software.

\section{Curriculum Design}

In order to further enhance students' grasp of microcomputer application system, Microcontroller Theory and Applications course curriculum design a separate calculation of credits. The topics of curriculum design is arranged at the end of the semester to students, so that students can do the preparatory work during the holidays, next semester two weeks time independent. Curriculum design entitled "8-channel precision analog data acquisition design, requires students to homemade PCB board microcontroller and precision AD chip design analog voltage acquisition, display and communication transmission system. Encourage students to use the embedded RTOS Small RTOS51 or of $\mu \mathrm{C}$ / OS-II curriculum design for learning embedded System and lay the basis of [17].

\section{Teaching effectiveness}

Micro-projects to drive the implementation of the teaching methods to stimulate students 'enthusiasm for learning and delving into the microcontroller spirit, most of the students' ability to be greatly improved. Students to use the microcontroller to design a variety of electronic systems, and to participate in national and provincial competitions, achieved very good results. In 2011 National Undergraduate Electronic Design Contest, the students of our hospital Third prize; recent 5th "Challenge Cup" Guangdong Students' Extracurricular Scientific Work Competition, our students get the seven provincial second prize, a national second prize, a first prize of Guangdong Province, Guangdong Province four provincial third prize. The nearly 2-year students participate in 10 patent applications, which authorized The student's thesis (design) by the "bully" weight "learn" light "technique" progress "carrot and stick", "learning" technique "both 
excellent paper was significantly improved. Graduates to adapt to society's ability to adapt the work significantly strengthened greatly enhance the level of jobs than ever before, the past three years have graduates hired well-known single-chip enterprises "Luminary Micro Company".

\section{Conclusion}

CDIO engineering education model based micro-project-driven teaching methods in the implementation of SCM courses allow students to accept the single-chip engineering exercise to improve their professional capacity, to achieve seamless connectivity with enterprise. Break the original single, closed system of teaching, and the establishment of wide caliber, professional engineering curriculum education framework and strong applications, heavy practice innovation system, the formation of the "theory and practice two combined, curricular and extracurricular two teaching contest two learning employment Combining innovative training model. Teaching reform, have greatly improved the abilities of students and theoretical level, learning to follow-up courses, graduation design and employment help.

Implementation of new teaching methods, so that teachers teaching ability, level to obtain more Great progress, promote research, teaching, teaching and research, and professional quality of teachers is enhanced, the formation of the teachers and students benefit from dual and have encountered the sustainable development of a good situation.

\section{References}

[1] Wei Cuiping, Wu Jikai. Assessment based on constructivist the pharmacy college specialties pharmacology experiment grade [J]. Education and career, 2010,47 (20) :114-116.

[2] The CDIO Initiative. The CDIO? Standards [EB / OL]. [2012 -05 -14].

[3] Wang Shuo Wang, Hong Chengwen. CDIO: the classic mode of the Massachusetts Institute of Technology engineering education: based on the the CDIO syllabus of interpretation [J]. Polytechnic Higher Education Research, 2009,28 (4):116-119.

[4] Zhou aiqing, Kui Xiuhui, Qu Youtian. Discussion on the Teaching Reform of Single-chip Computer Base on Mode CDIO at Vocational College [G] / / Proceedings of the 2010 10th IEEE International Con-ference on Computer and Informa-tion Technology. Bradford, UK,2010:21202123.

[5] Xu Xiangmin, Dong Jing Yuan, Xing Xiao-Fen. Innovative Talents and Electronic Design Contest mode to explore[C]. China Electronic Education Association Higher Education Branch 2010 Proceedings, 2010.

[6] Zhang Peng years. Visit Thoughts: SEM Kongxian Chen, vice president of sharing the new understanding of the "new three-center theory [EB / OL]. (2011-12-01) [2012-02-28] http:// www. ncbuct. com/news/xiaonei/2011-12-01/1393. html.

[7] Chen Dongsong, Sun Yangchun. Engineering Colleges personnel training mode CDIO engineering education pathway[J]. Modern Education Management, 2011,31 (11) :34-37.

[8] Joely, Liu Yinsheng. Exploration based on The CDIO the SCM reform of teaching methods [J]. Heilongjiang Science and Technology Information, 2011 (33): 196.

[9] Lin Yong Jiang, Wei agricultural construction, paragraph obviously. Project teaching: the selection of application-oriented teaching mode [J]. Chinese university teaching, 2010,29 (10):3335 .

[10] the four security $\mathrm{Fu}$. Constructivist learning theory, under the guidance of the Project Teaching Method [J]. Chinese university teaching, 2011,30 (2) :56-58.

[11] Sun liter. "Successful" students, "the mother of success" [J], Shandong Education and Research, 2001,26,5 [12] Wang Tianbao, CHENG Wei-Dong. Innovative engineering talents training model based on CDIO research and practice: the practice of engineering education reform of Chengdu University of Information [J]. Higher Education of Engineering, 2010,28 (1) :25-31.

[14] Zhuxiang Qing Hu Wan, Chen Honghua, et al. Multifunctional MCU experiment system [J]. Laboratory Research and Exploration, 2012,31 (4) :41-44.

[15] Tianhai Mei Zhu Baoping, Chen Aiping. Based on the practice of the comprehensive reform of the CDIO model[J]. Experimental Technology and Management, 2011,28 (4) :130-132 